\title{
ADVANCING Women of Color in STEM through Meaningful Mentoring: Key Observations from the Jackson State University ADVANCE Institutional Transformation Project
}

\section{Introduction}

As increasing numbers of underrepresented minority groups enter into higher education, the call for institutions to provide more diverse, equitable, and inclusive work and learning environments have prompted much investigation into the role of mentoring in faculty development and career advancement (Guarino and Berden, 2017; Esnard, Cobb-Roberts, Agosto, Karanxha, Beck, Wu, and Unterreiner, 2015; Irby, 2014; Mack, Watson, and Camacho, 2013; Haring-Hidore, 1987). Yet, despite the abundance of literature on mentoring, many questions remain unanswered regarding what works in the area of mentoring, faculty development, and career advancement for women of color in Science, Technology, Engineering, and Mathematics (STEM) fields as well as the Social and Behavioral Sciences. Some enduring questions that institutional leaders, college deans, department chairs, and faculty would do well to consider include the following: What aspects of the mentorship relationship are most significant to mentee success? What are the most effective organizational structures for faculty mentoring programs? Should the approach used in mentoring differ when the mentees are underrepresented minorities or women in traditionally male fields of study? Can a thoughtfully developed mentoring program contribute to an institution's overarching commitment to the retention, and advancement of women of color in STEM disciplines?

These questions helped guide the planning of the Jackson State University ADVANCE Institutional Transformation Project (JSU ADVANCE IT) - a National Science Foundation funded project that sought to transform the institutional climate and culture for women in STEM at a Historically Black College and University (HBCU) in the South. Determining what 
constitutes meaningful mentoring in this type of institutional context demands that we define and explain a few terms that are used somewhat uniquely here. In the case of the JSU ADVANCE IT Project, particular attention was devoted to understanding the institutional climate for mentoring those who self-identify as women in STEM as well as those who identify as women of color. Women of color is used here not to erase the uniqueness of experiences of individual racial or ethnic minority groups, but rather to highlight the need for inclusiveness when examining women in STEM at HBCUs. When overall numbers of women in STEM disciplines is low, there is a need to both address issues of gender bias, which crosses all racial/ethnic lines, without losing sight of the added layer of racial/ethnic distinctiveness and diversity which can influence women in STEM differently. Using women of color also signals the intentional alignment of the JSU ADVANCE IT Project with the work of forums such as the STEM Women of Color Conclave, which is recognized as a central space for the creation, debate, and dissemination of information about women of color in higher education. ${ }^{1}$ Just as women of color is intended to cast a wide net, so too is the use of the term STEM. At JSU, the social and behavioral science disciplines are housed physically and administratively within the College of Liberal Arts and the traditional science, technology, engineering, and mathematics (STEM) disciplines are within the College of Science, Engineering, and Technology. STEM, in this paper, is used to include all of these disciplines, except where explicitly differentiated.

Below we present an overview of relevant literature regarding mentoring, a description of the overall JSU ADVANCE IT Project, a discussion of the JSU ADVNACE Mentor Program, and a series of key observations and recommended actions for those committed to making

\footnotetext{
${ }^{1}$ Organizations designed to focus their attention on issues that influence the lives of women of color use this phrase as an alternative to the category African American or Black to reflect the diverse experiences and identities of women of color (and their allies) from other nations of origin or racial/ethnic groups. For additional information on the STEM Women of Color Conclave visit their website--SWOCC About https://www.conclave-swoc.net/about.
} 
mentoring a more intentional and meaningful part of institutional faculty development efforts.

The Mentoring Program components and related key observations yield useful insights on mentoring that may be applied in similar institutional contexts to promote the effective retention, career advancement, and overall job satisfaction of women of color in STEM. Insights from the JSU ADVANCE IT Project may also be relevant in shaping institutional transformation efforts which position all members of the campus community to benefit from a comprehensive approach to faculty development that is rooted and grounded in a commitment to developing a robust culture of mentorship. This examination of the JSU ADVANCE IT Project, specifically the JSU ADVANCE Mentoring Program, therefore, positions women of color in STEM (at an HBCU in the South) at the intersection of conversations on designing mentoring that promotes career advancement and institutional transformation.

\section{Perspectives on Mentoring in Higher Education}

\section{Mentoring Defined and Redefined}

The literature on mentoring within higher education has traditionally defined mentoring as a one-to-one, mentor-protégé construction in which a more experienced mentor guides, advises, coaches, or shares skills with a less experienced mentee (Montgomery, 2017; Sorcinelli and Yun, 2007). In this type of top-down version of mentoring, the relationships are thought to be most effectively implemented when mentor and mentee participate in the matching process, establish clear goals for the relationship, set clear and frequent feedback and communication, and provide not only academic but also psychosocial support and assistance with work-life balance, and integration into the academic culture (Nick, Delahoyde, Prato, Mitchell, and Siktberg, 2012; Berk, Berg, Mortimer, Walton-Moss, and Yeo, 2005). More recent professional development and faculty development literature has expanded the traditional definition of mentoring to 
include informal, short-term, and peer-to-peer mentoring networks (Montgomery, 2017). In the context of the JSU ADVANCE IT Project and the JSU ADVANCE Mentoring Program, mentoring is redefined more broadly as a combination of activities including formal one-to-one style mentoring, informal small group mentoring, career coaching, research networking, and professional development activities, designed to provide comprehensive support for faculty retention, career advancement, community building, research productivity, and institutional transformation.

\section{Mentoring and Faculty Development}

The influence of mentoring on faculty in higher education is quite compelling. Mentoring helps to ensure that individual faculty achieve their full potential in terms of all aspects of faculty roles and responsibilities (Girves, Zepeda, and Gwathmey, 2005). It allows for constructive dialogue on topics that include obtaining funding, manuscript preparation and publishing, grant writing, research design, long-term career planning, and understanding promotion and tenure (Feldman, Arean, Marshal, Lovett, and O'Sullivan, 2010). Mentoring also provides opportunities for new faculty to receive advice on navigating departmental politics and institutional culture (Bates and Boreland, 2014). It has been shown to improve faculty morale, increase self-confidence, contribute to more work-family balance, and lower levels of job-related stress (Nick, et al., 2012; DeJanasz and Sullivan, 2004). Faculty who are mentored also tend to do a better job of distributing their time between their various roles, resulting in greater productivity in terms of publications, external funding, and securing timely promotion than those who are not mentored (Nick, et al., 2012; Feldman, et al., 2010).

Mentoring not only helps to meet the needs of individual faculty, but it also provides benefits for academic departments and for the overall organizational and institutional culture 
(Thomas, Bystydzienski, and Desai, 2014). Mentoring promotes a more communal campus climate by providing space for increased departmental collegiality and by establishing an infrastructure to promote professional advancement and faculty success as foundational, institutional priorities (Bates and Borland, 2014). As faculty receive the support needed to be successful professionally, not only does their level of individual job satisfaction improve, but the institution experiences "increased retention and improved sense of community and professional identity" (Nick, Delahoyde, Prato, Mitchell, and Siktberg, 2012, p. 7). Institutions of higher education may, therefore, position themselves for a competitive advantage by focusing on faculty development with an emphasis on mentoring (DeJanasz and Sullivan, 2004, p. 275). In this way, planning and implementing mentoring programs for faculty is essential and potentially transformative; however, identifying a mentoring model that takes into consideration the unique racial, gender, and institutional context of women of color in STEM at HBCUs comes with multiple layers of complexity.

\section{Mentoring Women of Color in STEM}

The documented benefits of structured mentoring for women of color in higher education has for the most part centered on the use of mentoring as a tool to help address underrepresentation and to support institutional transformation in the areas of diversity, equity, and inclusion (Griffith and Sears, 2019). In one of the earliest and often-cited studies on women of color in higher education, Maids of Academe (2008), Debra Harley recommends that those interested in improving the work climates for women of color at predominately white institutions should provide "networking, mentoring, and better support for research and publications" to support career advancement and to help the women of color achieve balance between research, teaching, and service (Harley, 2008, p. 31). Guarino and Gordon (2017), like Harley suggest that 
within higher education women tend to engage in more service and teaching work than their male counterparts - often to the detriment of their career advancement. An approach to helping women faculty overcome these potentially career stalling obstacles is through strategic mentoring programs that are uniquely designed to increase the research productivity and overall professional success of underrepresented scholars (Irby, 2014; Mack, Rankins, and Winston, 2011; Evans and Cokley, 2008; Gregory, 2001).

Despite the clear benefits of mentoring, not all universities have formal structured mentoring programs as a part of their faculty development plans. The lack of institution-wide commitments to and infrastructure for mentoring has direct implications on women of color in STEM. Recent scholarship focusing on faculty development and broadening participation suggests that women and other minorities who are in academic disciples where they are traditionally underrepresented may be particularly vulnerable in terms of career advancement when access to structured mentoring opportunities are not available (Murakami, 2014; Mack, Rankin, and Winston, 2013; Harley, 2008; Niemeiser and Gonzalez, 2004; Smith, Smith, and Markham, 2000). The expectation is that when formal mentoring programs are not available, informal mentoring relationships will be established, but quite often these informal or spontaneous relationships are formed between individuals who share similar social characteristics, such as gender, class background, and social status (Girves, 2005). As such, underrepresented faculty, and women of color in STEM in particular, are "at a disadvantage" compared to their peers or colleagues in terms of forming mentoring relationships central for academic and professional integration (Girves, 2005, p. 455). They may very well be the only woman or person of color in their department, which certainly might make forming mentoring relationships more challenging. Crawford and Smith (2005) confirm the difficulty and contend 
that creating their own avenues for mentoring is exactly what women of color have done in the absence of formal senior-level mentors. Women of color have historically met their mentoring needs through a variety of "peer strategizers or peer colleagues" who helped them meet their short term goals (Crawford and Smith, 2005, p. 57). Crawford and Smith, however, do not consider these group or peer engagements to be legitimate mentoring experiences in the long run because they do not offer the same type of access to resources, skills, knowledge and insights for career advancement that a formal mentor would provide.

\section{Alternative Mentoring Models with Implications for Women of Color}

The emergence of mentoring networks is a promising means of achieving the benefits of traditional mentoring for women of color in STEM at HBCUs using a blended mentoring model. In recent years, much more attention has begun to be placed on the mentoring network model (Hanover Research, 2014). In this model, early-career faculty build robust networks by engaging multiple mentoring partners in non-hierarchical, collaborative, cross-cultural partnerships to address specific areas of faculty activity, such as research, teaching, working towards tenure, and striking a balance between work and life, departmental bias/culture and institutional politics (Soccinelli and Yun, 2007). Janasz and Sullivan (2004) contend that the rationale for the shift from the traditional mentoring model to the new methods are linked to increasing demands and expectations of faculty to participate in outreach, recruitment, online teaching, and fundraising as well as traditional research, teaching and service. Compounding these new expectations, are limited resources, increased diversity of student and faculty populations; and the changing nature of the relationship between faculty (assistant, associate, full) and administrators (Janasz and Sullivan, 2004). As such, academic institutions are encouraged to see a professor's career as something that demands multiple mentors who will help the faculty member develop various 
career competencies - beliefs, identities, knowledge, skills, networks, and relationships

(DeJanasz and Sullivan, 2004, p. 273).

The recognition of mentoring networks and group mentoring as a new trend in higher education has not completely displaced the traditional model. A mentoring program at the University of North Carolina was designed to address the mentoring and support needs of associate (mid-career) professors making the transition into full professorship. To achieve the program goals, they established a mid-career planning process, a vertical-dyad mentoring program for women in STEM, as well as formal and informal peer mentoring programs for faculty within and across disciplines (Buch, Huet, Rorrer, and Roberson, 2011). This model allowed for multiple alternatives for mentoring engagement while simultaneously providing women in STEM with targeted and formalized mentoring. It provided the best of both mentoring models.

Establishing mentoring as an institutional priority is essential for HBCUs as well as any other type of higher education institution interested in broadening participation and creating a more equitable and collegial institutional culture. Making the mentoring experiences personally and professionally meaningful and relevant for women of color in STEM at HBCUs becomes equally important, because as their needs are met the overall quality of mentoring offered has the potential to be elevated. However, failure to develop a formal institutional infrastructure for mentoring means that institutions may undermine their own efforts to recruit and retain a diverse faculty population which also compromises efforts to transform HBCUs into high research productivity institutions (Iglesias, 2014). Failure to prioritize mentoring means that even when women of color in STEM at HBCUs are hired, they are left to navigate the full teaching load (typically four, 3-credit hour undergraduate courses), initiating a research agenda, committee 
service, heavy student advising loads, and ever- increasing expectations to publish and secure grants often without adequate support for professional development. Establishing mentoring as an institutional priority is necessary, and the JSU ADVANCE IT Project components, particularly the JSU ADVANCE Mentoring Program, were designed to help point a way toward mentoring that meaningfully met the needs of women of color in STEM at an HBCU.

\section{BACKGROUND: The JSU ADVANCE IT Project}

\section{Project Goals, Objectives, and Components}

Funded from 2010-2015, the JSU ADVANCE IT Project had four general goals: 1) to advance the careers of all women faculty in STEM disciplines by reinforcing their career and professional development; 2) to develop and support a network of research and career mentors for women faculty in the STEM disciplines; 3 ) to foster a climate and culture which seeks the inclusion of all faculty regardless of gender and race; and 4) to establish a proactive disposition regarding the assessment of university policies, procedures, and practices, which ensures the greatest contributions from all members of the institutional community.

The foundational goals were aligned to three strategic JSU ADVANCE IT Project objectives: 1) to establish research, career, and tenure and promotion mentoring relationships that are specifically designed for STEM junior women faculty; 2) to establish visibility initiatives designed for STEM mid-career faculty to support them in obtaining increased exposure for their research scholarship; and 3) to establish leadership development designed for STEM women who are seeking to advance into academic administration at all levels. The three essential objectives were fulfilled through a set of interrelated project components which included: a summer writing retreat, a formal faculty mentoring and career development program, an 
international visibility initiative, a formal academic leadership program, a campus climate and social science study, a bias awareness initiative, an institutional policy review initiative, as well as a comprehensive program evaluation plan to help measure impact. This multi-pronged programmatic approach allowed the JSU ADVANCE IT Project team to begin the work of exploring the most effective strategies for transforming the institutional climate and promoting career advancement for women in STEM at an HBCU in the South. The task of exploring institutional transformation at an HBCU in the South meant that attention would be directed to women of color. Though, women of color were part of the racial majority on campus, within the STEM disciplines they were underrepresented in tenure-track faculty positions, in senior faculty (or full professor) positions, as well as in senior administrative leadership roles. From its inception JSU ADVANCE was focused on transforming the institution for all faculty, specifically women in STEM, by examining the unique mentoring needs and practices of women of color in STEM at an HBCU in the South because very little attention had been directed to women of color in STEM at HBCUs when the project was initially funded.

The JSU ADVANCE IT Project was designed to promote the career advancement of women in STEM through a series of strategically designed components. Each of these program components focused on aspects of faculty life for women scholars at different levels of the professoriate. The four components listed below are illustrative of the efforts taken to support career advancement by targeting the need to increase scholarly productivity through publishing and securing external grants via a Summer Writing Retreat; the need to expand engagement in international research collaborations via the Visibility Program; the need to have access to coaching and training when navigating the transition from faculty to academic administration via the Leadership Sabbatical; and the need to have professional and research mentors at different 
stages of career development via a formal Mentoring Program. In this paper the emphasis is on the formal JSU ADVANCE Mentoring Program.

\section{The JSU ADVANCE Mentoring Program}

The mentoring component of JSU ADVANCE was a multi-dimensional mentoring program that included both traditional, one-to-one mentoring dyads, as well as small group mentoring workshops aimed at supporting the tenure and promotion of STEM junior women faculty. To position the program for success and institutional adoption, mid-career and senior faculty were involved in establishing the criteria for success, and key administrative leaders were engaged in the early stages of defining the activities to be included in the mentoring initiative. The collaboratively conceived formal mentoring program included: a) an application process for mentees and mentors; b) pairing of mentees with a mentor from the home institution; c) the pairing of mentees with an external career coach: a successful scholar from outside of the mentee's home institution who provides guidance in the area of research and scholarly agendas, expanding professional networks, and research collaborations; d) a mandatory orientation, "The Importance of Mentoring in Career Development," that outlined the mentoring expectations; e) the development of an Individual Development Plan, which set the parameters and goals for the mentoring relationship; and f) Interactive Mentoring Workshops, with time built in for one-onone engagements between mentees and external workshop facilitators covering topics such as developing the dossier, developing a personal research niche, and promoting one's work. Over the course of the first few years of the JSU ADVANCE IT Project, the mentoring component was implemented as originally conceived, and as needed, it was modified in order to most effectively meet the mentoring needs of the participants. 


\section{The Original JSU ADVANCE Mentoring Model}

The JSU ADVANCE Mentoring Program was initially designed based on models that were proven effective in other institutional and industry contexts, namely, the mentor/mentee model. The JSU ADVANCE leadership team added to this model not only an internal mentor but also an external career coach. The objective of having both was to ensure that participants in the program were integrated into the culture of their respective departments with the support of their internal (on campus) mentor while also ensuring that the participants established (or restablished as needed) a strong research agenda and career plan with the support and guidance of an external (off campus) accomplished scholar and champion for broadening participation. The mentor-mentee pairings were critical parts of the initial application process for both mentors and mentee.

What quickly became apparent is that establishing positive internal mentoring pairings was more difficult than expected, as women in the respective discipline were at times reluctant to apply to the program because of fears about having their career, research, or scholarly productivity needs exposed to colleagues who may not have been supportive. There seemed to be a problem in terms of how mentoring in general was viewed, as well as a problem in how much support women of color felt within their respective academic units. Compounding these challenges, their normal workload often meant that finding time to disconnect from campus and family responsibilities in order to travel to meet an external research mentor was not feasible. Unfortunately, the Mentoring Program activities began to be viewed as another task to add to the already long list of things to do. In short, the formal mentor-mentee pairing aspect of the JSU ADVANCE Mentoring Program, as initially conceived, did not sufficiently meet the needs of the women faculty who participated. 


\section{Expanding the JSU ADVANCE Approach to Mentoring}

In the face of these limitations, program leaders opted to expand other aspects of the formal mentoring program, namely the small group formal workshops on career development topics. As mentioned previously, in these workshops women from a variety of departments came together to learn about designing career development plans, preparing for tenure and promotion, navigating departmental politics, and collaborating on grant funded projects. These groups met once or twice per month and addressed topics typically covered with a mentor. They allowed for flexibility in terms of attendance. The groups were also arranged so that women of color and champions of gender equity were invited to present on panels to provide a diversity of insights and perspectives on various career advancement and mentoring issues. Occasionally, external speakers - usually women of color in STEM with professional connections to HBCUs, were invited to facilitate these workshops. After the formal workshops, time was reserved for more personal engagement and interactions during lunch or dinner events. This structured small group approach to mentoring proved to be much more amenable to the faculty demands of the participants, and they particularly seemed to prefer opportunities to connect and share ideas with institutional leaders and invited workshop facilitators.

Expansions to the original design of the JSU ADVANCE Mentoring Program continued after the third year review. With feedback from reviewers and data from participant feedback, the focus of the mentoring initiatives shifted to include greater emphasis on seeking informal mentoring networks beyond the institution. Women in STEM who were eligible to participate in the grant funded activities, were supported with travel funds to attend the annual STEM Women of Color Conclave, a professional forum for women in higher education. This space offered opportunities for the participants to attend sessions on topics that were relevant to their unique 
professional, disciplinary, and social support needs. At these annual meetings women were immersed in an intellectual space where they were not underrepresented, and there they were able to connect to a network of other women of color in STEM for research collaborations, social support, and resource sharing. The mentor-mentee model was again expanded to encourage women in STEM to participate in the Opportunities for Under-Represented Scholars Program (OURS). This online post-graduate certificate program provided intensive professional development and training for women of color in STEM who had aspirations for academic leadership. Embedded in the program were opportunities to access mentoring, research development, professional networks, and career coaching that would typically be gain through on-campus mentoring initiatives.

\section{Key Observations from the JSU ADVANCE Mentoring Program}

The process of planning, implementing, assessing, and modifying the JSU ADVANCE Mentoring Program allowed ample opportunities to gather key observations about mentoring women of color in STEM at an HBCU in the South. These key observations served as guides as the project leaders pivoted and modified the mentoring activities to appropriately support participants in achieving their professional development and career advancement goals.

\section{Mentoring Key Observation \#1}

The part of the formal mentoring program that was most valuable to the women of color was the time to work with external facilitators on creating career development plans and research agendas. Those sessions included both a formal presentation from an expert as well as time for small group discussions or one-on-one work-sessions with the facilitator. Practical worksessions that allow for brainstorming, asking questions, and sharing of ideas in a non-threatening 
and collegial environment were deemed to be very useful opportunities to devote dedicated time to research and scholarly endeavors. Making mentoring meaningful requires that mentoring engagements occur in safe spaces and result in a tangible output.

\section{Mentoring Key Observation \#2}

Structured (yet less-formal) group mentoring workshops proved to be much more feasible and amenable for the women of color in STEM at JSU. The group mentoring approach created spaces for women faculty to engage informally with institutional leaders and colleagues in other departments and colleges thereby strengthening their on-campus visibility as active contributors to the institutional mentoring and faculty development enterprise. Additionally, the group mentoring events that featured external facilitators created on campus opportunities to build professional networks and obtain a clear view of how women in STEM at other HBCUs have navigated the journey of career advancement. Making mentoring meaningful requires that mentoring activities blend information sharing and professional networking.

\section{Mentoring Key Observation \#3}

A comprehensive, institutional mentoring culture needed to be cultivated. Individuals at every level needed to promote mentoring as a fundamental part of the professional development cycle. With respect to the JSU ADVANCE Mentoring Program, there were initial concerns among some participants that engagement in the program would be a sign of some deficiency in their research skills or competencies that they needed a mentor to correct. This perception speaks to a broader institutional climate in which faculty mentoring is not necessarily viewed as essential and foundational to a healthy intellectual community. Making mentoring meaningful requires a culture in which everyone has a mentor and everyone models good mentorship.

\section{Mentoring Key Observation \#4}


The modifications made during the implementation of the JSU ADVANCE Mentoring Program and the outcomes of the other JSU ADVANCE IT Project components revealed that the aims of the mentoring intervention were being achieved in unexpected project activities.

The Summer Writing Retreat Component, for example, served as a space in which the women of color felt more comfortable being transparent about their respective professional and personal obstacles and concerns. The community building activities and discussions of scholarly productivity, which were a centerpiece of the writing retreats, allowed for mutual sharing of strategies to overcome work and work-life obstacles.

Additionally, though the dedicated time and space for scholarly writing provided during the retreat was intended to be primarily for early career women faculty, many of those who participated were mid-career or senior faculty who took advantage of the writing retreat as a means to reignite their research or shift into a new research focus area-revealing the need for mentoring initiatives designed for every career stage. While mentoring was not the focus of the writing retreats, they became a space in which mentoring objectives were achieved: development of sense of belonging, support for scholarly productivity, advancement of research agendas, and career-life integration coaching for example were all observable features of the faculty writing retreats. Making mentoring meaningful requires flexibility and openness to defining (and finding) mentoring relationships where they naturally happen within the full spectrum of faculty development activities.

\section{Conclusion: Advancing Women in STEM through Meaningful Mentoring}

The JSU ADVANCE IT Project began with a set of ambitious goals and project components that were all designed to promote the career advancement of women in STEM and 
thereby transform the institution. The Mentoring Program planning, implementations, and modifications revealed useful observations that shed light on what it takes to make mentoring a useful component in the career development of women of color in STEM at an HBCU. From the JSU ADVANCE Mentoring Program key observations we learned that mentoring which leads to overarching institutional transformation requires engagement, investments, and strategic action at multiple levels. Our concluding discussion, therefore, presents strategic action steps for institutional leaders, academic departments chairs/deans, and individuals who are committed to the cultivation of enduring institutional transformation in the area of mentoring.

\section{Institutional Commitments to Mentoring}

At the institutional level it is essential to invest in mentoring. Institutional leaders demonstrate their care and concerns for faculty when they prioritize the collection and use of data on faculty development needs to drive professional development activities. Make mentoring a central part of new faculty orientation, and integrate attention to high quality mentoring into annual evaluations for administrators and faculty. Remember that faculty, who are most often underserved by traditional mentor-mentee programs or completely overlooked in informal mentoring networks, need a mechanism by which their voices are heard in the process of planning and implementing mentoring and other faculty development programs. Ensure that the objectives of the mentoring program are collaboratively determined, clearly communicated, and consistently assessed, evaluated, and refined. These measures help to ensure that the structured mentoring program of the institution is comprehensive yet flexible enough to meet the needs of the faculty while also addressing broad institutional priorities. Invest in building a robust and exciting mentoring culture; it can be the foundation for long term institutional success. 


\section{Departmental Commitments to Mentoring}

Department chairs and academic deans also have a role to play in creating a robust mentoring culture that attends to the needs of underrepresented populations in their respective academic colleges and departments. As such it is imperative that they converse with women faculty and become familiar with mentoring and gender equity best practices. Our work demonstrates vividly that what works in mentoring will differ based on the expressed needs of those being mentored and the unique climate, culture, and characteristics of the academic unit. When department chairs are clear on faculty needs, they are best positioned to advocate for necessary resources and programs to meet those needs within and across different departments. Department chairs set the tone of collegiality within the academic unit. From this position, department chairs have unique opportunities to model mentorship in the following ways: (a) by having a professional mentor, (b) by seeking out mentees, (c) by integrating community building into regular faculty meetings, (d) by sharing resources on best practices in mentoring students and colleagues, and (e) by establishing semi-structured mentoring groups (especially for new faculty) as a means of creating non-threatening opportunities for conversations on career advancement to happen.

When a department includes only one person (or a few persons) from an underrepresented group, part of the work of building a culture of mentorship may require being creative in identifying relevant mentors even if it means going outside of the department. Additionally, chairs and deans may make special efforts to connect women of color to external mentoring opportunities that target the career advancement of women of color in STEM fields. In the absence of a formal institutional mentoring program, department chairs and deans may also proactively recognize and celebrate, not only those individuals who provide excellence in 
mentorship, but also those who exhibit creativity in securing the mentoring that they need to advance their careers.

\section{Colleagues' Commitment to Mentoring}

Colleagues, who are supporters of broadening participation, increasing equity, and mitigating unconscious bias may also assist in building an institutional mentoring culture. Though racial, gender, ethnic, age, and disciplinary barriers may exist, supports and champions of gender equity can contribute to the work of providing mentoring both within and beyond their respective departments by looking for opportunities to relate to and get to know the women of color in the department and college. Exerting the effort to find and establish common ground whether in the realm of family life, hobbies, research interests, and teaching challenges goes a long way toward building trust and inclusivity for individuals who may be the only member of an underrepresented group within an academic unit. Mentors help to integrate new people into the fabric of the intellectual community, and that very meaningful work is needed for all members of the campus community — not only for those with whom senior scholars have a natural affinity or observable similarities. Doing the work of integrating all persons into the scholarly community contributes significantly to the equitable retention and advancement of women of color of STEM.

The support for colleagues, especially those colleagues who are underrepresented in their respective fields, may take a number of different forms: inviting them to join a research team, including them as co-PIs on grant funded projects, looking for ways to engage women of color in international research projects or study abroad opportunities, and helping to create informal opportunities for all members of the faculty to connect and collaborate are just a few. Perhaps most significantly, scholars who have very well established networks may make mentoring 
meaningful by sharing their professional network in order to connect women of color (particularly new faculty) to mentors and/or resources at other institutions who might more effectively meet their needs. These actions enrich the departmental culture, advance the institutional goals of equity and broadening participation, and ultimately increase faculty job satisfaction by promoting a positive work climate and culture.

\section{Individual Commitment to Mentoring}

In the absence of formal institutional mentoring programs, consistently implemented departmental mentoring procedures, or informal mentoring practices of colleagues, there are still ways for women of color in STEM to access the mentoring that they need to succeed. What we know from the JSU ADVANCE IT Project and the JSU ADVANCE Mentoring Program is that mentoring is available in myriad forms. Connecting with champions both within and beyond one's home department is a first step. Being proactive in building positive work networks is also an excellent way to establish collegial relationships that allow safe spaces to voice concerns and learn about the institutional climate and culture - both of which are essential parts of navigating the internal politics of the institution. Getting to know people outside of one's home department also opens doors for collaborations on research, innovative teaching projects, and grants. These informal, individual actions allow women of color access through their peers to knowledge and insights about the institution that would typically come from a mentor. The informal interactions also serve a social function of significantly decreasing feelings of isolation and increasing feelings of belonging at the institution.

Within or across academic departments and disciplines, women of color may also engage in more structured efforts to access the benefits of mentoring (if a formal institutional mentoring program is not available). Establishing a writing or research group is a great way to increase 
writing productivity, and online or virtual writing groups make it possible to maintain collegial relationships with scholars in your field from other institutions. Making writing social and having people with a similar drive toward scholarly productivity and research activity is essential to the work of prioritizing time for building a research agenda. Whereas a formal mentor would typically help to guide the development of a scholarly research and publishing agenda, in the absence of a formal mentoring program, individual women can support each other in their career advancement efforts through self-structured writing and research groups.

Additionally, individual faculty women of color may get the mentoring that they need by strategically building and establishing their scholarly and professional networks. A simple way of doing this when funds for conference travel are limited, is to take advantage of professional social media networks where research, teaching, and scholarly accomplishments are highlighted and shared. Connect with the campus communications office for assistance in setting up professional quality social media profiles and websites that showcase research expertise and recent publications or teaching innovations. Use those sites exclusively to connect with scholars and professional organizations in their field of expertise. Cultivate connections with local community organizations related to their primary field of expertise. In very different ways, building a professional network does the work that having an established mentor in one's field of study could do; it creates opportunities for collaborations and opens doors for new opportunities beyond the home institution.

Finally, an essential way to secure the mentoring that is needed is to simply ask for a mentor. Understand that mentorship is the cornerstone of career advancement. The need for a second opinion, a recommendation, or a more informed perspective on an issue will arise. The most direct way to access mentorship is to identify individuals whose career trajectories, work- 
life balance, professional reputations, and research productivity you admire. Have a conversation with them about establishing a mutually beneficial mentoring relationship. Determine the timeframe and specific goals of the relationship. Agree upon mechanisms for accountability and a means for measuring the success of your relationship. Commit to getting the mentoring that you need.

Mentoring is key to career advancement. Whether initiated by an individual, a colleague, a department chair/dean, or as part of a broad institution-wide program, mentoring that really works requires engagement and commitment at multiple levels. Mentoring that speaks to the unique realities of faculty life for women of color in STEM at an HBCU in the South not only needs to engage multiple levels of institutional stakeholders, but it must also engage various models for mentorship. The modified and expanded version of the JSU ADVANCE Mentoring Program along with the unanticipated mentoring moments that happened in the other JSU ADVANCE IT Project components confirm an important insight. When mentoring is viewed through the critical lens of women of color in STEM at an HBCU in the South, the way forward toward individual career advancement, departmental attainment of gender equity, and institutional transformation all come into clearer focus. 


\section{REFERENCES}

Bates, D.C., Borland, E. (2014). Fitting in and stalling out: Collegiality, mentoring, and role strain among professors in the sciences at a primarily undergraduate institution. Polymath: An Interdisciplinary Arts and Science Journal, 4(2). Southern Illinois University

Belcher, W.L. (2019). Writing your journal article in twelve weeks: A guide to academic publishing success, 2nd Ed. Chicago, IL: U of Chicago P.

Blake-Beard, S., Bayne, M. L., Crosby, F. J., \& Muller, C. B. (2011). Matching by race and gender in mentoring relationships: Keeping our eyes on the prize. Journal Of Social Issues, 67(3), 622-643. doi:10.1111/j.1540-4560.2011.01717.x

Buch, K., Huet, Y., Rorrer, A., \& Roberson, L. (2011). Removing the barriers to full professor: A mentoring program for associate professors. Change: The Magazine of Higher Learning, 43(6), 38-45.

Crawford, K. and Smith, D. (2005). The we and the us: Mentoring African-American women. Journal of Black Studies, 36(1), 52-67. https://doi.org/10.1177/0021934704265910.

DeJanasz, S.C. and Sullivan, S.E. (2004). Multiple mentoring in academe: Developing the professorial network. Journal of Vocational Behavior, 64(2), 263-283.

http://dx.doi.org/10.1016/j.jvb.2002.07.001.

DeJanasz, S. C., Sullivan, S. E., Whiting, V. and Biech, E. (2003). Mentoring networks and career success: Lessons for turbulent times. Academy of Management, 17(4), 78-93.

Esnard, T., Cobb-Roberts, D., Agosto, V., Karanxha, Z., Beck, M., Wu, K., \& Unterreiner, A. (2015). Productive tensions in a cross-cultural peer mentoring women's network: A Social capital perspective. Mentoring \& Tutoring: Partnership In Learning, 23(1), 19-36. doi:10.1080/13611267.2015.1011035

Evans, G. L., \& Cokley, K. O. (2008). African American women and the academy: Using career mentoring to increase research productivity. Training And Education In Professional Psychology, 250-57.

Feldman, M. D., Arean, P. A., Marshal, S. J., Lovett, M., \& O’Sullivan, P. (2010). Does mentoring matter: Results from a survey of faculty mentees at a large health sciences university. Medical Education Online, 15, 1-8.

Girves, J. E., Zepeda, Y., and Gwathmey, J. K. (2005). Mentoring in a post-affirmative action world. Journal of Social Issues, 61(3). 449-479. DOI: 10.111/j.1540-4560.2005.00416.x.

Gregory, S. T. (2001). Black faculty women in the academy: History, status and future. Journal of Negro Education, 70

Griffith, F. and Sears, K. P. (2019, Sept. 10). Effectively mentoring women of color on the college campus: A holistic and intersectional ecology (HIE) model. Diverse Issues in Higher Education. https://diverseeducation.com/article/154495/

Guarino, C.M. and Borden, V. M. H. (2017). Faculty service loads and gender: Are women taking care of the academic family? Research in Higher Education, 58.6, 672-694.

Hanover Research (2014). Faculty mentoring models and effective practices. Retrieved from www.hanoverresearch.com.

Haring-Hidore, M. (1987). Mentoring as a career enhancement strategy for women. Journal of 
Counseling and Development, 66(3), 147-48.

Harley, D. (2008). Maids of academe: African-American women faculty at predominately white institutions. Journal of African American Studies, 12(1), 19-36.

Iglesias, K. (2014). The Price of prestige: A Study of the impact of striving behavior on the expenditure patterns of American colleges and universities. Seton Hall University Dissertations and Theses. http://scholarship.shu.edu/dissertations/1938

Irby, B. J. (2014). Advancing women of color in the academy: Research perspectives on mentoring and strategies for success. Mentoring \& Tutoring: Partnership in Learning, 22(4), 265-268. doi:10.1080/13611267.2014.946280

Mack, D., Watson, E.D., \& Camacho, M.M. (2013). Mentoring faculty of color: Essays on professional development and advancement in colleges and universities. Jefferson, NC: McFarland Publishers.

Mack, K., Rankins, C., \& Winston, C. (2011). Black women faculty at historically Black colleges and universities: Perspectives for a national imperative. In H. Frierson \& W. Tate (Eds.), Beyond stock stories and folktales: African Americans' paths to STEM fields (pp. 149-164). Bingley, England: Emerald Group Publishing Limited.

Mack, K., Rankins, C., \& Woodson, K. (2013). From graduate school to the STEM workforce: An Entropic approach to career identity development for STEM women of color. New Directions For Higher Education, 163, 23-34. doi:10.1002/he.20062

Murakami, E. T., \& Núñez, A. (2014). Latina faculty transcending barriers: Peer mentoring in a Hispanic-serving institution. Mentoring \& Tutoring: Partnership in Learning, 22(4), 284301. doi:10.1080/13611267.2014.945739

Nick, J. M., Delahoyde, T. M., Prato, D. D., Mitchell, C., Siktberg, L. (2012). Best practices in academic mentoring: A model for excellence. Nursing Research \& Practice, 1-9. doi: $10.1155 / 2012 / 937906$

Niemeier, D.A., \& Gonzales, C. (2004). Breaking into the guild masters club: What we know about women science and engineering department chairs at AAU Universities. National Women's Studies Association Journal, 14(1), 157-171.

Schick, K., Hunter, C., Gray, L.C., and Poe, N.T. (2011). Writing in action: Scholarly writing groups as faculty development. Journal on Centers for Teaching and Learning. Research Gate.

Smith, J.W., Smith, W.J., \& Markham, S.E. (2000). Diversity issues in mentoring academic faculty. Journal of Career Development, 26(4), 251-261.

Sorcinelli, M. D. and Yun, J. Y. (2007). From mentor to mentoring networks: Mentoring in the new academy. Change: The Magazine of Higher Learning. Retrieved from http://works.bepress.com/marydeane_sorcinelli/7/

Thomas, N., Bystydzienski, J., and Desai, A. (2015). Changing institutional culture through peer mentoring of women STEM faculty. Innovative Higher Education, 40(2), 143-157. DOI: $10.1007 / \mathrm{s} 10755-014-9300-9$ 